\title{
A INTERDISCIPLINARIDADE NAS NOVAS CONFIGURAÇÓES CURRICULARES DA EDUCAÇÃO SUPERIOR BRASILEIRA: O CASO DOS BI DA UFBA
}

\author{
THE INTERDISCIPLINARITY IN THE NEW CURRICULAR \\ CONFIGURATIONS OF THE BRAZILIAN HIGHER EDUCATION: THE \\ CASE OF THE BI OF THE UFBA
}

\author{
Gabriel Swahili Sales de Almeida \\ Doutorado em Educação pela Universidade Federal da Bahia. \\ Professor Adjunto da Universidade Federal da Bahia. Bahia - BA - Brasil \\ swahili@ufba.br
}

\begin{abstract}
Resumo: A universidade contemporânea tem se deparado com desafios de ordem social, epistemológica e estrutural que requerem uma profunda reflexão acerca de seu estatuto e função social. No contexto brasileiro, uma série de reformas incompletas agravam ainda mais a chamada crise da universidade. Este artigo busca discutir os sentidos da interdisciplinaridade nos bacharelados interdisciplinares (BI) da Universidade Federal da Bahia a partir de uma pesquisa documental sobre o processo de criação desse formato de cursos. Foram utilizados como fontes a legislação federal, resoluções e pareceres da UFBA e documentos de referência para os BI tais como seus projetos político-pedagógicos, compreendendo o período de 2006 a 2016. A partir da análise, pudemos concluir que a ausência de uma política institucional especificamente voltada à interdisciplinaridade constituiu um fator limitante à afirmação dos BI como uma nova arquitetura acadêmica.
\end{abstract}

Palavras-Chave: Bacharelados Interdisciplinares. Educação Superior. Interdisciplinaridade. Reestruturação Universitária. REUNI.

Aвstract: The contemporary university has encountered social, epistemological and structural challenges that require a profound reflection on its status and social function. With the objective of understanding these new configurations, this article seeks to discuss the meanings of interdisciplinarity in the Bacharelados Interdisciplinares (Undergraduate Interdisciplinary Programs) of the Universidade Federal da Bahia (Federal University of Bahia) from a documentary research of the process of creation of these. Federal level legislation, resolutions, documents and Institutional Development Plan of UFBA and reference documents for BI were used as sources, such as the Political Pedagogical Projects, covering the period from 2006 to 2016. From the analysis, we could conclude that the absence of an institutional policy specifically focused on interdisciplinarity imposed on the $\mathrm{BI}$, a project initially thought as a means of reformulating the university, that were formatted to fit the same, operating mainly on an institutional disciplinary frame.

KeYwords: Undergraduate Interdisciplinary Programs. Higher Education. Interdisciplinarity. University Restructuring. REUNI. 
As crescentes mudanças da contemporaneidade têm exigido novos modos de produção e difusão de saberes. Questôes como a função social do fazer acadêmico, atual estatuto da ciência, globalização/mundialização da sociedade da informação, mercantilização do ensino superior, dentre outras, exigem que a universidade, locus privilegiado dos processos de produção e difusão, elabore respostas e tome posição.

As discussóes relativas ao papel da universidade, apesar de prementes, não são novas. Milton Santos (2000) e Anísio Teixeira (2005), para citar apenas dois exemplos de vulto, discutiam e desenvolviam, há décadas, projetos alternativos de experiência universitária, considerando o papel da instituição no desenvolvimento do país, da cultura nacional e da posição/ relação do Brasil no sistema-mundo. Apesar das reiteradas tentativas, os esforços para reestruturar o sistema universitário brasileiro foram muitas vezes sustados por processos antidemocráticos, impedindo o pleno florescimento da universidade como fomentadora da chamada 'alta cultura nacional' e promotora de uma sociedade mais justa.

No último decênio, algumas modificaçóes têm sido ensaiadas na estrutura do sistema de educação superior do Brasil. Com a promulgação do Programa de Apoio a Planos de Reestruturação e Expansão das Universidades Federais (REUNI) em 2007, intensificou-se o processo de reformulação da arquitetura curricular da universidade brasileira, que já sofria pressóes por mudanças tanto por parte das transformaçóes do paradigma de conhecimento quanto do avanço das chamadas políticas neoliberais para o setor estimuladas por organismos de financiamento internacionais como o Fundo Monetário Internacional e o Banco Interamericano de Desenvolvimento.

Nesse contexto, a Universidade Federal da Bahia ganha papel de destaque por protagonizar, com o projeto 'UFBA Nova', uma tentativa de reformulação da arquitetura acadêmica da universidade. Visando dotar a universidade brasileira de uma estrutura curricular flexível, interdisciplinar e socialmente relevante e que articule graduação e pós-graduação, a UFBA nova, com a instituição dos bacharelados interdisciplinares, se constitui como uma das pioneiras no Brasil na adoção de regimes modulares de formação em ciclos. Tal modelo de universidade incorpora elementos dos colleges norte-americanos e proposiçóes fundantes do Processo de Bolonha, introduzindo um ciclo terminal de formação não-profissional, 
de caráter propedêutico e geral, que serve como pré-requisito para cursos acadêmicos e profissionais posteriores (SANTOS; ALMEIDA, 2008).

Assim, este artigo, busca discutir os sentidos da interdisciplinaridade nos BI's da UFBA a partir de uma pesquisa documental de seu processo de criação.

\section{Interdisciplinaridade: uma abordagem conceitual}

Conforme argumenta Naomar Almeida Filho (2008), o atual modelo de educação superior no Brasil se caracteriza pela predominância, em sua estrutura curricular, de perspectivas superadas de formação profissional e acadêmica, desregulamentação da educação, reformas universitárias incompletas - ou frustradas - e, epistemologicamente, uma concepção linear e fragmentadora do conhecimento, alienada em relação à complexidade dos problemas da sociedade e da natureza. Essa concepção de universidade consegue, por vezes, cumprir sua função como formadora, credenciando profissionais tecnicamente competentes, contudo, por omissáo, permite que eles saiam dela incultos, no sentido de não desenvolverem uma cultura científica e humanística.

Como espaço hegemônico da produção e reprodução de saber, as universidades ocupam, historicamente, papel decisivo na formalização, configuração e legitimação do conhecimento científico. Nessa longa trajetória, o conhecimento produzido tem sido acumulado de maneira fragmentada e compartimentalizada pelas mais diferentes disciplinas e especialidades, que muitas vezes se ignoram mutuamente e trabalham de maneira isolada, ainda que enfoquem o mesmo objeto de estudo.

Segundo Santos e Almeida (2008), a reforma universitária proposta pelo REUNI, encarnada na UFBA principalmente pelo modelo do Bacharelado Interdisciplinar (BI), buscaria suplantar as limitaçóes de campos de saber existentes nos projetos pedagógicos dos cursos profissionais, que impóem precocidade na escolha da carreira, um dos grandes fatores de evasão estudantil, bem como o descompasso entre a rigidez da formação e a diversidade de competências requeridas hodiernamente pelo mundo do trabalho. Esta é uma das principais propostas dos BI: desenvolver um modelo de formação superior mais integrador, abrangente e flexível, capaz 
de fomentar a formação dos estudantes universitários em eixos ou temas relevantes da cultura contemporânea. Uma investigação mais detalhada de como a interdisciplinaridade é apreendida e praticada nos Bacharelados Interdisciplinares da UFBA contribui, assim, para compreender melhor as reestruturaçóes propostas pelo REUNI à arquitetura curricular da universidade brasileira.

Muito se tem discutido acerca do conceito de ciência na atualidade, tanto acerca das fundaçôes epistemológicas do fazer científico e seus critérios de verdade - especialmente em decorrência dos avanços da física quântica - quanto sobre a influência do crescente desenvolvimento das tecnologias de comunicação e informação na produção de conhecimento e da multiplicidade dos processos de investigação científica diante da "emergência da complexidade" (MORIN, 1981) e seus novos paradigmas. Esses fatores estão intimamente ligados a um rearranjo no mundo do trabalho em escala global e apontam para uma redefinição de como são estabelecidas as disciplinas e currículos nas universidades.

$\mathrm{O}$ conflito entre o conhecimento generalizado e a especializaçáo não é recente. A história da ciência, especialmente no Ocidente, tem se construído na tensão entre esses dois pólos. Apesar da divisão aristotélica, depois retomada pela Igreja Católica, na Europa clássica e medieval não havia a preocupação de estabelecer limites significativos entre as várias formas e tradiçóes de conhecimento. Com a difusão do método de Descartes e a consolidação das instituiçóes universitárias no continente europeu, houve uma associação crescente entre a organização das cátedras e estruturas administrativas das instituiçóes de educação superior, as tradiçóes de pesquisa e de ensino específicas e as carreiras profissionais. Do alinhamento desses três fatores, e no lastro da expansão das universidades, as disciplinas foram formatadas, envolvendo, além de critérios epistemológicos, critérios políticos (PAVIANI, 2008). Esse modelo disciplinar, partindo do projeto cartesiano, acentuou a compartimentalização e fragmentação do modo como interpretamos o mundo.

Conhecer, segundo essa perspectiva, é separar sujeito de objeto e então dividir o objeto em partes, de modo a reduzi-lo ao menor componente possível. Nesse cenário de hegemonia da abordagem estritamente cientificista, duas verdadeiras revoluçôes atravessaram a universidade no século XX: a quântica e a informática. Elas trouxeram à baila a complexidade, 
que segundo Nicolescu (1999, p. 18) se "mostra por toda parte, em todas as ciências exatas ou humanas, rígidas ou flexíveis"; em resposta às necessidades de uma tecnociência sem freios, sem valores e sem outra finalidade além da eficácia pela eficácia, acabou por pulverizar a pirâmide na qual se organizavam as disciplinas em um "verdadeiro big-bang disciplinar." Ocorre que

Este big-bang disciplinar tem enormes consequências positivas, pois conduz ao aprofundamento sem precedente do conhecimento do universo exterior e assim contribui volens nolens para a instauração de uma nova visão do mundo. [...]

[...] Edgar Morin tem razão quando assinala a todo momento que o conhecimento do complexo condiciona uma política de civilização. (NICOLESCU, 1999, p. 16 e 18)

Essa "visão de mundo" ou "política de civilização" é um componente intrínseco ou algo que tem sido imputado à interdisciplinaridade? Esse tem sido um debate controverso. Alguns autores veem a interdisciplinaridade menos como uma consequência das mudanças produtivas geradas pela tecnociência desenfreada, ou pelo atual estágio do capitalismo, ou pela emergência de novos paradigmas do conhecimento ocasionada pelos avanços da própria ciência, e mais como um movimento ou projeto. Para Gattás e Furegato (2007, p. 86),

O movimento da interdisciplinaridade surge na Europa, notadamente na França e na Itália, em meados da década de 1960, época em que se insurgem os movimentos estudantis, reivindicando um novo modelo curricular para a escola e para a universidade.

É importante ressaltar que alguns autores, como Bianchetti e Jantsch (2002), não vêm o desenvolvimento da interdisciplinaridade como um mero processo espontâneo de grupos docentes e discentes nas universidades, já que a partir de 1969 um grupo de estudiosos reunidos pela Organização para a Cooperação e Desenvolvimento Econômico (OCDE), "discutiu durante vários dias o tema e elaborou um documen- 
to que se tornou matriz dos debates e escritos posteriores." (JANTSCH; BIANCHETTI, 2002, p. 19)

Paviani (2008) concorda que o projeto da interdisciplinaridade tem como objetivo a realização humana em sua plenitude, mas defende que a interdisciplinaridade náo surge de um mero ato da vontade ou de uma decisão externa, e sim da necessidade de apreender o objeto ou o problema de pesquisa como um todo. Assim, o desenvolvimento da ciência, por ter 'esbarrado' na complexidade, teria deixado de ocorrer linearmente, pelo acúmulo de conhecimentos de disciplinas cada vez mais especializadas, e passado a depender, a partir dos anos 50 do século passado, cada vez mais da fecundação recíproca de diversas áreas de conhecimento, da transferência de conceitos, métodos e problemas entre elas, isto é, de um contexto interdisciplinar.

As concepçóes de interdisciplinaridade como um ato de vontade do sujeito do conhecimento ou como um desdobramento quase natural de uma epistemologia emergente sofrem críticas por serem vistas como a-históricas, em parte por considerarem a interdisciplinaridade uma série de procedimentos fundados exclusivamente na subjetividade de seus participantes, o que impediria a construção da genealogia, situada no contexto da produção humana, do 'objeto' interdisciplinaridade. Para Jantsch e Bianchetti (2002), a produção da existência, submetida a um modelo de sociedade cujos limites e horizontes são determinados por um pragmatismo funcional e utilitarista que emana da concepção e da prática dos empresários, é o principal aspecto a ser considerado no que tange à emergência da interdisciplinaridade, e isso precisa ser encarado frontalmente por educadores e responsáveis pelas políticas educacionais.

Seria a interdisciplinaridade uma questão de atitude? Uma postura adotada diante da complexidade? Uma forma de fazer científico que o sujeito do conhecimento opta por desenvolver? O produto das mudanças no capitalismo contemporâneo? Para nós, os fatores que apontamos anteriormente convergem para produzir o atual destaque da interdisciplinaridade, a saber: as condiçóes e exigências geradas pelo mundo do trabalho, somadas ao desenvolvimento da técnica e da ciência, com as respectivas alteraçôes paradigmáticas frente à complexidade. Esses elementos, porém, não determinam nem a existência nem o modo como a interdisciplinari- 
dade pode se desenvolver; para isso, a eles se soma o fazer humano, como apontam Gattás e Furegato (2007, p. 86-87):

A interdisciplinaridade é o exercício de alguma coisa que se faz entre um objeto voluntarista (objeto que acreditamos fazer, temos vontade de fazer, uma espécie de estímulo para fazer) e, ao mesmo tempo, é qualquer coisa que vai acontecendo, está sendo feita, quer queiramos ou náo.

Discutimos o que provoca a interdisciplinaridade no seu sentido, digamos, filogenético: o conjunto de fatores que, historicamente, possibilitou, se não o surgimento da interdisciplinaridade enquanto fenômeno, pelo menos a sua ampla consolidaçáo dentro da academia contemporânea. A ontogênese da interdisciplinaridade vai reproduzir, em menor escala, os fatores filogenéticos que a geraram; mas o que, além desses macro-elementos, motiva a prática interdisciplinar? Para Zanettini-Ribeiro et al, (2013, p. 6), "na pesquisa interdisciplinar, são os objetos de estudos que definem a disciplina." Essa leitura se afina com a ideia de que a complexidade em si promove uma mudança de abordagem. É neste sentido de interdisciplinaridade: como uma posiçáo adotada frente ao objeto ou processo, que Teixeira (apud Silva; Pinto, 2009, p. 6) aponta que "o que torna uma atividade interdisciplinar náo é o sujeito nem o objeto, mas os aspectos processuais da atividade".

Paviani (2008) defende que, inversamente ao que muitas vezes se faz parecer, a interdisciplinaridade é, em última instância, uma defesa das disciplinas e não sua eliminação. Ou seja, uma base disciplinar sólida é um pré-requisito para o desenvolvimento de um projeto interdisciplinar. As disciplinas são, simultaneamente, produtos históricos da evolução da ciência, ferramentas epistemológicas do fazer científico e um arranjo políticoinstitucional de controle do conhecimento. Por responder, em maior ou menor grau, a esses três eixos que compóem o conhecimento disciplinar, a interdisciplinaridade enquanto categoria emergente está vinculada a um projeto de mudança na cultura das instituiçôes, conforme Gomez e Orrico (2004, p. 1): "um exercício transversal da racionalidade, perpassando não só as fronteiras das disciplinas, quanto as fronteiras das atividades seto- 
riais, no escopo e abrangência da produção e transmissão do conhecimento científico."

Portanto, é fundamental avaliarmos os nexos entre os distintos formatos institucionais do/no sistema universitário e a abordagem interdisciplinar. A noção de "arquitetura acadêmica", conforme apresentada por Franco et al (2013), pode nos ajudar nesta avaliação, já que extrapola a ideia de estrutura organizacional de ensino e pesquisa, seja nos níveis de graduação seja de pós-graduação. Essas se referem, antes, a modalidades organizacionais associativas, de caráter formativo-científicas, concebidas e implantadas como indutoras de qualidade da chamada Educação Superior e que têm como pressuposto um processo explícito ou implícito de aferição de resultados por critérios de referência estabelecidos. Objetos de políticas públicas, essas arquiteturas acadêmicas e os marcos regulatórios aos quais elas estão vinculados estáo sob a pressão dos diversos interesses - com sua variedade de intençôes e disputas - envolvidos nas suas formulaçôes em todos os níveis institucionais: tanto as reformulaçóes no sistema federal de ensino superior quanto as políticas universitárias locais têm o poder de dificultar ou facilitar o ensino e a pesquisa interdisciplinar. E qual tem sido a abordagem interdisciplinar adotada pelas normatizaçóes federais e universidades no país? Segundo Carlos e Zimmerman (2006, p. 2):

O modismo decorrente da rápida e superficial assimilação da interdisciplinaridade no sistema educacional brasileiro ainda perdura até hoje, podemos até afirmar que se tornou um jargão no meio educacional, pois a interdisciplinaridade aparece com muita frequência no discurso de professores, em projetos pedagógicos e planos de ensino. Entretanto, a prática da interdisciplinaridade amiúde resulta em conquistas aquém das expectativas e, além disso, a execução, controle e avaliação das iniciativas interdisciplinares apresentam dificuldades que desafiam e, muitas vezes, desanimam os professores.

A presença da interdisciplinaridade, ou ao menos de um discurso sobre a interdisciplinaridade, se consolidou no cenário educacional brasileiro no fim dos anos 90 do século passado, quando os Parâmetros Curriculares Nacionais passaram a preconizar a necessidade de um ensino interdisci- 
plinar, ainda que as condições nas instituições de ensino não permitissem uma presença efetiva da prática interdisciplinar, que se tornou muitas vezes esvaziada de significado. Para Silva e Pinto (2009), no contexto brasileiro, a proposição e orientação no sentido da interdisciplinaridade vem sofrendo de uma leitura simplificadora, derivada de modelos educacionais focados em aspectos considerados mais pragmáticos, relacionados diretamente às necessidades do mercado de trabalho e à ênfase técnica frente à arte e aos valores humanísticos. Talvez por derivar de uma adaptação verticalizada e apressada, a prática interdisciplinar no Brasil encontre tantos percalços:

Presente como orientação e princípio nos documentos oficiais e nos textos dos projetos pedagógicos, a interdisciplinaridade, entretanto, continua, por uma série de razóes, como uma meta ainda distante de ser alcançada, como um fazer que se almeja, mas que ainda carece de encontrar caminhos para sua efetiva consecução. (SILVA; PINTO, 2009, p. 3).

Há, dessa forma, um desencontro entre a prescrição da prática interdisciplinar - feita unilateralmente, via marcos regulatórios - e um fomento dessa prática a partir da dinâmica de produção de saberes dos espaços de pesquisa e formação, o que é um reflexo de certo "descompasso entre um dever fazer e um como fazer o que se deve." (SILVA; PINTO, 2009, p 6) Modelos puramente prescritivos de interdisciplinaridade "geram expectativas e mostram caminhos incertos, muitas vezes com mais idealizaçóes do que concretudes" (Zanettini-Ribeiro et al, 2013, p. 18), e têm fácil apelo, já que parece que a interdisciplinaridade, como descrevem Gattás e Furegato (2007, p. 89) "é uma tarefa inacabada porque não se consegue definir com exatidão o que vem a ser vinculação, reciprocidade, interação, comunidade de sentido ou complementaridade entre as várias disciplinas." Resta-nos saber se essa incompletude é intrínseca ao fazer interdisciplinar ou é apenas reflexo da imaturidade do projeto da interdisciplinaridade.

Em um contexto de crescente controle do administrativo sobre o pedagógico, do burocrático e da hiper-produtividade sobre a pesquisa dentro das universidades, há de se pensar sobre os discursos do novo, táo caros à área de educação, mas muitas vezes ineficazes - ou, poder-se-ia dizer, eficazes em dar sobrevida a antigas práticas. Cabe discutir a interdiscipli- 
naridade, mas não apenas a sua prática em contexto didático, e sim o seu percurso e impactos na estrutura institucional do sistema universitário.

\section{REUNI, projeto UFBA Nova e IHAC}

Instituído pelo Decreto no 6.096, de 24 de abril de 2007, o REUNI é um programa de reestruturação pedagógica e ampliação física do sistema federal de educação superior que integra o Plano de Desenvolvimento da Educação (PDE) e tem como objetivo principal a expansão das universidades, buscando fortalecer o acesso e a permanência nas mesmas.

Ressaltamos que a Universidade Federal da Bahia teve um papel preponderante no processo de elaboração do REUNI. Como parte da campanha de reeleição do então Reitor Prof. Naomar Almeida Filho, no início de 2006, foi apresentado à comunidade da UFBA um programa de trabalho que realçava o tema de reestruturação curricular, com a intenção de fomentar na instituição uma reforma universitária verdadeira - isto é, abrir cursos experimentais, interdisciplinares e com novas modalidades; renovar os projetos acadêmico-pedagógicos; reduzir as barreiras entre os níveis de ensino; modificar a arquitetura curricular, e não apenas tímidos rearranjos institucionais e financeiros. Um dos itens do programa foi chamado UFBA Nova, referência direta ao "movimento da Escola Nova que, na década de 1920, sob a liderança de Fernando de Azevedo e Anísio Teixeira, preconizava uma renovação radical em todos os níveis de ensino no Brasil.” (UNIVERSIDADE FEDERAL DA BAHIA, 2010, p. 157)

A partir da sua apresentação na ANDIFES, o Projeto UFBA Nova tornou-se Projeto Universidade Nova, e angariou o apoio do Ministério da Educação, que o usou como base para o programa em escala nacional REUNI. Objeto de intenso debate político e acadêmico, o Programa procurou respeitar a autonomia das IFES e foi reconfigurado a partir das mais diversas contribuiçôes, contrastando com as reformas anteriores, que, por partirem de iniciativas governamentais desarticuladas da vivência das universidades, se mostraram extremamente problemáticas. Ainda assim, a abertura ao diálogo não impediu que o REUNI sofresse pesados ataques de uma parcela do movimento estudantil, que classificou o programa como parte do projeto neoliberal de desmonte da uni- 
versidade pública e gratuita. Segundo Naomar Almeida, em "25 universidades federais, houve tumulto e violência em reunióes de Conselhos Universitários; 14 Reitorias foram invadidas; 9 dessas ocupaçôes somente terminaram mediante emissão de mandados judiciais de reintegração de posse." (ALMEIDA, 2008, p. 189)

As análises e críticas - algumas sem compreensão aprofundada do programa proposto - de segmentos do movimento estudantil foram compiladas num documento denominado Livro Cinza Dossiê REUNI (COORDENAÇÃO NACIONAL DE ENTIDADES PELA REVOGAÇÃO DO REUNI, 2009). Elaborado por diretórios e centros acadêmicos de diversas universidades do país, o dossiê buscava apresentar as dificuldades enfrentadas pelos estudantes em suas instituiçóes com a implantaçáo do REUNI, especialmente no que toca a infraestrutura, programas de permanência e superlotação das salas de aula, além de solicitar a revogação presidencial do referido Programa. A primeira versão do documento foi entregue ao MEC, com endereçamento ao então presidente Luís Inácio Lula da Silva, no ano de 2008. Em 2009, uma segunda edição foi elaborada.

Na UFBA, a reestruturação curricular proposta pelo REUNI possibilitou a incorporação de elementos do projeto original da UFBA Nova. Buscando inspiração nas reformas da formação superior propostas por Anísio Teixeira para a UnB, no Processo de Bolonha e nos colleges dos EUA, essa reformulação pretendia incorporar, de maneira inovadora, um desenho capaz de desfazer o fosso entre os níveis, que hoje impede estudantes de graduação, mestrado, doutorado e mesmo de extensão compartilharem a vivência em sala de aula, bem como responder às demandas próprias e atuais de formação no contexto brasileiro, constituindo uma alternativa aos modelos de formação em graduação baseados nas universidades europeias do século XIX, já superadas em seus locais de origem, todavia vigorantes em nosso país.

Sem extinguir os cursos atuais e suas formas de ingresso, a UFBA adotou um regime de três ciclos de educação universitária, sendo o primeiro deles ciclos o Bacharelado Interdisciplinar (BI), uma nova modalidade de cursos oferecidos nos campos de: a) Artes, b) Ciência \& Tecnologia, c) Humanidades, d) Saúde. Todos os BI são estruturados de forma similar em cinco Eixos Curriculares: Eixo das Linguagens, Eixo 
Interdisciplinar, Eixo da Orientação Profissional, Eixo de Formação Específica e Eixo Integrador. Conforme os projetos pedagógicos dos BI, todos os eixos são cursados em paralelo, em uma base multi, inter e trans (MIT) disciplinar, e distribuídos em uma duração mínima de 6 semestres, com carga horária total mínima de 2.400 horas - aproximadamente trinta componentes curriculares com 2.040 horas mais as atividades complementares, de 360 horas. Essas atividades complementares compóem o Eixo Integrador dos Bacharelados e têm como função articular as duas etapas de formação do curso, a saber: Etapa de Formação Geral e a Etapa de Formação Específica. A estrutura curricular dos BI baseia-se nos conceitos de Bloco e Eixo Curriculares, definidos como conjunto de módulos (cursos, disciplinas, atividades, programas, trabalhos orientados) ofertados aos alunos durante o período letivo e divide os cursos em duas etapas: Etapa de Formaçáo Geral, nos três primeiros semestres do curso, e Etapa de Formação Específica, nos três últimos semestres. Os BI são cursos terminais e não-profissionais, cujas grandes áreas, entendidas como campos de saberes, práticas, tecnologias e conhecimentos, definidos de modo amplo e geral em termos de afinidade de seus objetos, métodos cognitivos e recursos instrumentais, servem como pré-requisito para ingresso nos Cursos de Progressão Linear (CPL), como ficaram conhecidos os ciclos de formação profissional.

Sobre os BI, Naomar Almeida Filho (2008, p. 20) explana: “Tratase de uma estrutura modular, interdisciplinar, flexível e progressiva, com garantia de mobilidade intra e interinstitucional." Essa modificação curricular pretende fornecer à universidade um modelo mais dinâmico e atraente. Um dos principais avanços dos $\mathrm{BI}$, em termos pedagógicos, está em substituir uma avaliação com quatro dias de prova - os famigerados vestibulares e exames nacionais - por uma avaliação processual e contínua, ao longo de três anos, feita por pelo menos 30 professores.

Para sediar esta nova modalidade de formação geral universitária, a UFBA criou, em 2008, o Instituto de Humanidades, Artes e Ciências Professor Milton Santos (IHAC), que conta atualmente com quatro bacharelados, um mestrado no Programa de Pós-Graduação em Estudos Interdisciplinares sobre a Universidade e um mestrado e um doutorado no Programa Multidisciplinar em Cultura e Sociedade. O IHAC, como uma das mais recentes unidades acadêmicas da Universidade Federal da Bahia, 
foi criado num momento de profunda transformação tanto da UFBA quanto da universidade brasileira, portanto, foi concebido para desenvolver atividades acadêmicas inovadoras. A homenagem ao geógrafo baiano Milton Santos, que empresta o nome ao Instituto, sintoniza a proposta de produção de saber interdisciplinar e socialmente engajado dessa nova UFBA com a prática acadêmica e humana desse ilustre intelectual. Os BI propóem-se a contribuir para a construçáo, no Brasil, de um modelo de educação superior compatível com os atuais modelos internacionais, guardando afinidades com os padrôes norte-americanos (colleges de origem flexneriana) e europeu (Processo de Bolonha), porém, como afirma Almeida (2008, p. 232), atentando ao que for pertinente para o contexto nacional e sem "submissão a qualquer um desses regimes de educação universitária." $\mathrm{O}$ autor esclarece:

$\mathrm{Na}$ realidade, há grandes diferenças ideológicas, formais e operacionais entre o BI da Universidade Nova, o college no modelo norte-americano e o Bachelor do modelo unificado europeu. Por um lado, a pré-graduação da universidade norte-americana é mais longa e mais densa, em termos curriculares, do que o $\mathrm{BI}$, exigindo dedicação exclusiva e, em muitos casos, residência nos campi. Por outro lado, as diversas versôes do primeiro ciclo do Processo de Bolonha (laurea trienale na Itália, license na França, bachelor na Inglaterra, bakkalaureat na Áustria etc.) têm estruturas de currículo já bastante especializadas, quase contraditórias com a essência interdisciplinar do BI. (ALMEIDA, 2008, p. 237)

A prática institucional de ciência produziu campos disciplinares rigorosamente delimitados, modelo ao qual a universidade tem mostrado resistência em romper. Teóricos defendem, então, que prática interdisciplinar se propóe a superar esse modelo estanque e fracionado de ciência: é uma abordagem para o estudo de temas e problemas complexos que náo podem ser reduzidos aos recortes mono-disciplinares. Mais do que abordagens independentes e paralelas do mesmo objeto por várias disciplinas diferentes, a interdisciplinaridade envolve e articula diversos campos disciplinares em um trabalho e discurso comuns: 
O enfoque interdisciplinar consiste num esforço de busca da visão global da realidade, como superação das impressốes estáticas, e do hábito de pensar fragmentador e simplificador da realidade. Ele responde a uma necessidade de transcender a visão mecanicista e linear e estabelecer uma ótica globalizadora que vê a realidade, em seu movimento, constituída por uma teia dinâmica de inter-relaçôes circulares. (LUCK, 1994, p. 72)

Ocorre que, independentemente da importância e potencialidade que uma reestruturação do sistema universitário federal como esta enseja, é preciso reconhecer a existência de grandes desafios a sua efetivação. Soma-se à complexidade da reforma de um sistema historicamente deficitário, em um país de dimensóes continentais, as dificuldades ocasionadas pelo contexto internacional diversificado e as mudanças epistemológicas que o fazer científico tem sofrido no cenário contemporâneo. É necessário ir além dos clichês que consideram os BI's ora como uma panaceia mágica que, de pronto, resolveria todos os problemas da chamada educação superior, ora como uma mera reproduçáo imposta pela política neoliberal. Ao se voltar para a experiência da nova UFBA é preciso manter em foco que o processo de transformaçáo se faz ao longo da prática refletida. Especialmente no espaço universitário, refletir de maneira crítica sobre a trajetória percorrida é indispensável para construir o próprio caminhar.

Ao nos debruçarmos sobre o corpus documental, pudemos constatar que a interdisciplinaridade dentro da UFBA padece da ausência de uma política global capaz de orientar seu desenvolvimento. Apesar da prática relativamente espalhada, até mesmo antes do advento do IHAC, as diversas medidas que foram ensaiadas buscando criar coerência entre elas não chegaram a constituir uma política institucional sólida. As medidas institucionais tomadas em relação à temática afetam - direta ou indiretamente - $\mathrm{o}$ assentamento dos BI na estrutura e cultura organizacional da universidade, porém, ainda carecem de consistência. Sendo pioneiro em termos de acesso via Sistema de Seleção Unificada (SISU), os BI e seus estudantes sofreram desqualificaçóes por supostamente não terem sido selecionados de maneira realmente meritocrática. Apenas com a aprovação da Resolução n ${ }^{\circ}$ 03/2013 do Conselho Acadêmico de 
Ensino, que estabeleceu a adoção do Exame Nacional do Ensino Médio (ENEM) e a adesão ao SISU/MEC, para ingresso geral nos cursos de graduação da UFBA, as diferenciaçóes na forma de ingresso entre estudantes do BI e do CPL foram minimizadas.

Outro exemplo desse tipo de incorporação gradual e em grande parte assistemática da interdisciplinaridade pode ser encontrado na Resolução $n^{\circ}$ 01/2013 do Conselho de Ensino Pesquisa e Extensão (CONSEPE), que regulamenta o aproveitamento da Açáo Curricular em Comunidade e em Sociedade (ACCS) para integralização curricular dos cursos de graduação e pós-graduação da Universidade Federal da Bahia. Ela estabelece que:

A multidisciplinaridade, a interdisciplinaridade e a transdisciplinaridade devem ser asseguradas pela relação dialética e dialógica entre diferentes campos dos saberes e fazeres necessários para atuação em comunidade e sociedade. (UFBA, 2013a, p. 01)

A valorização de uma abordagem MITdisciplinar (Multi, Inter e Trans) aparece nos documentos, muitas vezes, de forma figurativa, desacompanhada de meios adequados para sua concretização. Em contraste com as necessidades reais do IHAC na execução de seu projeto, essas medidas parecem pálidas. Quando da adoção do REUNI, parte das açôes de planejamento, gestáo e acompanhamento dos BI's seria realizada por outras unidades, de forma integrada ao IHAC. Para serem efetivadas, muitas das projeçóes e metas estabelecidas pelo Instituto precisariam tomar como base esse tipo de trabalho coordenado, como a Orientação Acadêmica proposta no projeto pedagógico dos BI's:

Para cada grupo de 45 alunos do BI, haverá um professor encarregado da Orientação Acadêmica que, em princípio, conduzirá o mesmo grupo ao longo do seu percurso acadêmico, até o final do curso. Dadas as características inovadoras do modelo BI, a Orientação Acadêmica será obrigatória para todos os alunos e regulamentada no projeto de organização e implantação do IHAC, como atribuição dos seus docentes. (UFBA, 2008, p. 34) 
Considerando os 64 docentes ativos e os 4251 discentes, mesmo a ambiciosa meta de Orientação Acadêmica com proporção de 45 alunos por professor não seria realizável. Em números atuais essa taxa seria de aproximadamente 62 estudantes para cada docente. Acreditamos que, longe de uma problemática do IHAC, desafios institucionais desse porte demandam uma abordagem mais global para serem solucionados, o que nos leva a questionar quais instâncias são responsáveis por tratar a temática, dentro da UFBA, no nível do planejamento e gestão.

Conforme o Art. $21^{\circ}$ do Regimento Geral da Universidade é a Pró-Reitoria de Ensino de Graduação (PROGRAD), que tem, dentre outras funçóes, o papel de coordenar, planejar, executar, assistir, supervisionar e fiscalizar as políticas de ensino de graduação. Em termos de política e gestão, a interdisciplinaridade - pelo menos em sua dimensão pedagógica - estaria, de acordo com o Art. $7^{\text {o }}$ do Regimento Interno da Reitoria, submetida à Coordenação Acadêmica de Graduação, subárea da Superintendência de Administração Acadêmica ligada â PROGRAD, a quem competiria, por meio do Núcleo de Planejamento Acadêmico da Graduação,

desenvolver projetos multi e interdisciplinares que integrem, no âmbito do ensino de graduação, atividades de cunho formativo para os estudantes, em articulação com outros programas e projetos desenvolvidos pela Universidade, incluídas as monitorias [...] (UFBA, 2013b, p. 11)

A Coordenação Acadêmica de Graduação é subdivida em coordenaçôes por áreas, da seguinte forma: a) Área I/C\&T - Superior em Tecnologia; b) Área II/BI, em Saúde; c) Área III/BI, em Humanidades; d) Área IV e V/BI, em Artes. A evidente departamentalização das coordenações aponta os limites institucionais para se pensar e praticar políticas integradas e interdisciplinares. Contraditoriamente, em vez de emergir e ser mantido a partir de uma política universitária em torno da interdisciplinaridade, o IHAC passa a encarnar, tanto em termos organizacionais quanto de pessoal, a prática interdisciplinar da UFBA. Isto é, partir da implantação dos $\mathrm{BI}$ recai sobre o IHAC a tarefa de potencializar a interdisciplinaridade no contexto da universidade. Esta função messiânica, além de inadequada 
dado o lugar que o Instituto ocupa no desenho institucional da UFBA, enfrenta resistências diversas:

Os Bacharelados Interdisciplinares possuem, ainda, em sua proposta características que confrontariam problemáticas enraizados na educação superior no Brasil. No entanto, percebe-se uma grande resistência tanto institucional como intelectual (membros gestores de diversos cursos) que deslegitimam este processo de renovação do ensino superior. Pode-se atribuir a isto dois fatores: primeiro, o processo de colonização que formou uma instituição com bases conservadoras que perduram até os dias atuais; e, o segundo, os interesses políticos e econômicos, que buscam em sua plenitude favorecer as elites brasileiras. (VERAS; LEMOS; MACEDO, 2015, p. 637)

Parte dessa resistência tem sido diluída pela ação de docentes, estudantes, gestores e técnicos do IHAC. Em grande medida, as soluçóes desenvolvidas emergem da prática cotidiana do Instituto para depois serem compartilhadas com outras unidades ou com a administração central, muitas vezes em longo trâmite. Um exemplo desse esforço foi a recente aprovação das diretrizes para reserva de vagas em componentes curriculares sem pré-requisitos dos Cursos de Progressão Linear para estudantes dos BI (Resolução n 03/2016 do Conselho Acadêmico de Ensino (CAE), 10 de agosto de 2016) (UFBA, 2016). Apesar de estar estabelecida no projeto de implantação dos BI, de 2008, como uma contrapartida das outras unidades em relação à adesão ao REUNI, a reserva de $10 \%$ de vagas por parte dos demais colegiados para estudantes oriundos do IHAC não se efetivava. Foram necessários sete anos de existência do Instituto para que uma normativa reforçasse uma política já estabelecida, mas sem concretização. Podemos notar, a partir da análise do texto, quais tipos de entraves a reserva de vagas aos BI enfrentou: a disponibilização de vagas não era feita de forma antecipada e a listagem dos componentes náo estava acessível; quando disponibilizadas, as vagas não eram reservadas na primeira fase de inscrição semestral, impossibilitando que boa parte dos estudantes do BI utilizassem 
a matrícula web, o que implicava muitas vezes em matrícula presencial de milhares de estudantes todo semestre; ausência de acesso ao planejamento acadêmico das outras unidades de modo que os colegiados dos BI pudessem propor ajustes.

\section{Conclusóes}

A análise documental aqui empreendida permitiu concluir que a ausência de uma política institucional especificamente voltada à interdisciplinaridade impossibilitou que os BI's, inicialmente pensados como meio de reformular a universidade, alcançassem este objetivo. No sentido inverso, os bacharelados interdisciplinares foram antes formatados de modo a se adequarem modelo universitário já existente. Afinal, a existência de marcos normativos não é, por si só, garantidora da incorporação de determinado procedimento na dinâmica das organizaçôes, como pudemos ver com a situação da reserva de vagas para estudantes dos BI's. A existência de garantias nominais ou formais nem sempre se traduzem, no que tange à interdisciplinaridade na UFBA, em práticas concretas. Ainda assim, a integração dos processos entre as unidades e, consequentemente, entre as áreas de conhecimento, pedem, além da ampla participação de todos os segmentos envolvidos, a mediação da administração central para dirimir dissensóes e bloqueios.

Como nos alerta Barros e Carvalho (2004), a má focalização e falta de informaçóes sobre a eficácia dos programas - portanto, de controle -, bem como a falta de integração, coordenação e articulação das açóes concorrem para sua baixa efetividade. Em muitos sentidos, a documentação revisada nos alerta que os BI's vêm operando sobre um 'chassi' institucional disciplinar. Isso, somado à já mencionada ausência de uma política institucional especificamente voltada à interdisciplinaridade, que seja capaz de emoldurar o projeto em que a UFBA foi pioneira, torna-se um fator preponderante para o quadro de improvisação, falta de avaliação sistemática e posterior adequação das açôes tomadas, o que tem limitado o desenvolvimento da chamada nova arquitetura acadêmica na UFBA. 


\section{Referências}

BRASIL. Decreto n 6.096 , de 24 de abril de 2007. Institui o Programa de Apoio a Planos e Reestruturação e Expansão das Universidades Federais - REUNI. Diário Oficial [da] República Federativa do Brasil, Brasília, DF, 24 de abril de 2007b. Disponível em: <http:/www.planalto.gov.br/ccivil_03/_Ato2007-2010/2007/Decreto/ D6096.htm>. Acesso em 20 Ago 2016

BARROS, Ricardo Paes de; CARVALHO, Mirela de. Desafios para a Política Social Brasileira. In: GIAMBIAGI, Fabio; REIS, José Guilherme; IRANI, André. (Org.) Reformas no Brasil: Balanço e Agenda. Rio de Janeiro: Nova Fronteira, 2004.

CARLOS, Jairo Gonçalves; ZIMMERMANN, Erika. Conceito de interdisciplinaridade: longe de um consenso. In: Anais ABRAPEC, Bauru, 2006.

COORDENAÇÃO NACIONAL DE ENTIDADES PELA REVOGAÇÃO DO REUNI. O Livro Cinza do REUNI - Dossiê Denúncia das Consequências do REUNI. 2009.

FRANCO, Maria Estela Dal Pai et al. Interdisciplinaridade e Formatos Institucionais. In: Simpósio Internacional sobre Interdisciplinaridade no Ensino, na Pesquisa e na Extensão - Região Sul, Florianópolis, 2013.

GATTÁS, Maria Lúcia Borges; FUREGATO, Antônia Regina Ferreira. A Interdisciplinaridade na Educação. In: Rev. RENE. Fortaleza, v. 8, n. 1, p. 85-91, jan./ abr.2007.

GÓMEZ, Maria N. G. de; ORRICO, Evelyn G. D. As políticas institucionais das configuraçóes interdisciplinares dos conhecimentos. Datagramazero, v. 5, n. 6, dez. 2004

JANTSCH, Ari Paulo; BIANCHETTI, Lucídio. Interdisciplinaridade e práxis pedagógica. Ensino em Revista, Uberlândia, v. 10, n. 1, p. 7-25, 2002.

LUCK, Heloisa. Pedagogia interdisciplinar: fundamentos teórico-metodológicos. Petrópolis, Rio de Janeiro: Vozes, 1994.

MORIN, Edgar. O problema epistemológico da complexidade. Rio de Janeiro: EuropaAmérica, 1981.

NICOLESCU, Basarab. O manifesto da transdisciplinaridade. Triom : São Paulo, 1999.

PAVIANI, Jayme. Interdisciplinaridade: conceitos e distinçóes. 2. ed. Caxias do Sul, RS: Educs, 2008.

SANTOS, Boaventura de Sousa; ALMEIDA FILHO, Naomar. A Universidade no século XXI: para uma universidade nova. Coimbra: Almedina, 2008.

SANTOS, Milton. Por uma outra globalização: do pensamento único à consciência universal. Rio de Janeiro: Record, 2000. 
SILVA, Luiza Helena Oliveira da; ; PINTO, Francisco Neto Pereira.

Interdisciplinaridade: as práticas possíveis. Revista Querubim, 2009, v. 5, p. 1-18.

TEIXEIRA, Anísio. Ensino superior no Brasil: análise e interpretação de sua evolução até 1969. Rio de Janeiro: EDUFRJ, 2005.

UNIVERSIDADE FEDERAL DA BAHIA (UFBA). Projeto Pedagógico dos Bacharelados Interdisciplinares. 2008.

UNIVERSIDADE FEDERAL DA BAHIA (UFBA). Memorial da Universidade Nova: UFBA 2002-2010. Salvador, Editora da UFBA, 2010.

UNIVERSIDADE FEDERAL DA BAHIA (UFBA). Resolução no 01/2013 do

Conselho de Ensino, Pesquisa e Extensão (Consepe), Salvador, 2013a.

UNIVERSIDADE FEDERAL DA BAHIA (UFBA). Resolução $n^{\circ}$ 11/2013 do

Conselho Universitário (CONSUNI), Salvador, 2013b.

UNIVERSIDADE FEDERAL DA BAHIA (UFBA). Resolução nº 03/2016 do

Conselho Acadêmico de Ensino (CAE), Salvador, 2016.

VERAS, Renata Meira; LEMOS, Denise Vieira da Silva; MACEDO, Brian Teles Fonseca. A trajetória da criação dos Bacharelados Interdisciplinares na Universidade Federal da Bahia. Avaliação (Campinas), 2015, v. 20, n. 3.

ZANETTINI-RIBEIRO, Cristina; FRANCO, Maria Estela Dal Pai; BORDIGNON, Luciane . Práticas de perspectiva interdisciplinar: categorias emergentes. In: SIIEPE Sul. EGC/UFSC, Florianópolis, 2013.

Recebido em I ${ }^{\circ}$ out. 2017 / Aprovado em I6 out. 2018

Para referenciar este texto:

ALMEIDA, G. S. S. A interdisciplinaridade nas novas configuraçóes curriculares da educação superior brasileira: o caso dos BI da UFBA. EccoS - Revista Científica, São Paulo, n. 47, p. 355-374. set/dez. 2018. Disponível em: <https://doi.org/10.5585/ EccoS.n47.7936>. 